International Journal of Engineering \& Technology, $9(3)(2020) 710-717$
International Journal of Engineering \& Technology
SPC
Website: www.sciencepubco.com/index.php/IJET
Research paper

\title{
Geotechnical sustainability in the United Arab Emirates - Sustainability rating tools
}

\author{
Ryan Sochanik * \\ Geotechnical Practice Manager, Atkins, Dubai \\ *Corresponding author E-mail: ryansochanik@hotmail.com
}

\begin{abstract}
Sustainability and the concept of sustainable development now forms part of governmental policy around the world. The United Arab Emirates is no different, recognising that its ecological footprint and continued growth require management of resources and waste streams. A fundamental part of this is sustainable construction and operation of civil engineering projects such as buildings, roads and airports. Geotechnical engineering is required on practically all civil engineering projects yet is often overlooked when design and construction decisions are being made regarding civil engineering sustainability. One of the most common ways to measure sustainability in civil engineering projects is through rating tools. Rating tools have grown and developed internationally for decades and are used across the world for various different projects (buildings, roads, infrastructure etc.). The United Arab Emirates have developed their own local ratings tools (and sustainability frameworks) and have mandated their use in certain projects. There is significant scope for geotechnical engineering to contribute to improving sustainability and rating tools are one element that can be developed. A detailed review of local and international ratings tools is carried out to understand where geotechnical engineering can currently contribute and the possibilities to improve geotechnical sustainability in the United Arab Emirates are discussed.
\end{abstract}

Keywords: Civil Engineering Sustainability; Geotechnical Engineering; Local Rating Tools; United Arab Emirates.

\section{Introduction}

The UAE is a constitutional federation of seven emirates founded in 1971. It is located in the North East of the Arab Peninsula with a land mass of approximately $71,023.6 \mathrm{sq} \mathrm{km}$. There is desert climate in the UAE with high temperatures in the summer (average maximum temperature is 45.0 degrees Celsius) and relatively high temperatures in the winter (the minimum average temperature is 13.0 degrees Celsius) (Statistic Centre Abu Dhabi). Typical average rainfall varies from $0 \mathrm{~mm}$ in the summer months to $13 \mathrm{~mm}$ in the winter months (Statistic Centre Abu Dhabi). The high temperatures combined with low rainfall means water scarcity is a concern in the UAE.

Sustainability and associated concepts (such as carbon footprint) are increasingly recognised as a fundamental part of managing the earth's resources. The need for sustainability in the UAE is recognised by the Government and included in development plans and agendas, such as Vision 2021 (United Arab Emirates, 2010). The objectives of the UAE Government are aligned to the UN Sustainable Development Goals (SDGs) and their 2030 Agenda (United Nations, 2015). Although significant improvements in environmental management have been made, in 2016 the World Wildlife Fund estimated that the United Arab Emirates is still amongst the countries with the highest ecological footprint in the world (World Wildlife Fund, 2016).

The UAE, and in particular Dubai, is known for its construction projects including the world's tallest building. Sustainability during construction and operation of these construction projects is recognised as a key part of the SDGs. Civil engineering, therefore, needs to continue and improve implementation of sustainability in engineering projects. This requirement, and the associated challenge for engineering, is well documented (for example, Pantelidou et al., (2012)).

Geotechnical engineering is a discipline of engineering involving any interaction with soil and rock (natural, manufactured or improved). Almost all civil engineering projects require geotechnical input through elements such as foundation design, excavation support and slope stability. In addition to multidisciplinary projects, there are standalone geotechnical projects such as cuttings and embankments. As a consequence, there is significant scope for geotechnical engineering to contribute to sustainability.

A companion paper (Sochanik, 2020) presents the current legislative framework for engineering sustainability in the United Arab Emirates. Three of the Emirates have either sustainability frameworks or rating tools to ensure minimum requirements are met and optimised sustainability performance is recognised. While the United Arab Emirates is proactive in sustainable policies, there are multiple opportunities to improve geotechnical engineering and civil engineering sustainability. One of the avenues available for increasing geotechnical sustainability is through development of the rating tools, both in the most commonly used engineering rating tools and those in use in the United Arab Emirates. 


\section{Sustainability rating tools - worldwide}

Internationally civil engineering has adopted various different tools to improve the sustainability of projects, primarily by being able to quantify how sustainable a project is. Rating tools are one method, where different key indicators are measured and assessed against best practice and an overall rating assigned. The rating systems build on mandatory requirements for "green" construction with the aim of encouraging new developments to go beyond the minimum requirements.

A brief description of the most commonly used ratings tools (worldwide) is presented to provide an understanding of their key objectives and goals.

\section{$\operatorname{BREEAM}(U K ; 1990)$}

BREEAM (Building Research Establishment Environmental Assessment Method) is recognised as the first sustainability assessment method for buildings and was created in 1990. Its stated aim is to "encourage continuous performance improvement and innovation by setting and assessing against a broad range of scientifically rigorous requirements that go beyond current regulations and practice" (BREEAM, 2014).

BREEAM measures a project's sustainable credentials in the following series of categories

- Energy

- Health and Wellbeing

- Innovation

- $\quad$ Land Use

- Materials

- Management

- Pollution

- Transport

- Waste

- Water

After assessment, the projects are certified and awarded a rating, based on the projects performance. The ratings are used to encourage companies to adopt the highest level of sustainability into their projects. The BREEAM ratings are Pass, Good, Very Good, Excellent and Outstanding and it is reflected in a series of stars on the BREEAM certificate.

BREEAM assessment and certification is possible for:

- Communities

- New Construction

- In-use (existing building performance)

- Refurbishment and Fit-Out

BREEAM infrastructure is discussed under CEEQUAL.

\section{LEED (USA: 2000)}

LEED, or Leadership in Energy and Environmental Design, is the most widely used green building rating system in the world. The LEED classification system assesses the design, construction and operation of high-performance structures across several categories:

- Integrative Process

- Location and Transportation

- Sustainable Sites

- Water Efficiency

- Energy and Atmosphere

- Materials and Resources

- Indoor Environmental Quality

- Innovation

- Regional Priority

LEED certification is valid for throughout the project life cycle (design, construction, operation and maintenance) and certification is grouped into five main categories:

- Building Design and Construction

- Interior Design and Construction

- Operations and Maintenance

- Homes

- Neighbourhood Development

Ratings are given to projects based on their performance in the categories. The ratings awarded to projects within the LEED certification are Certified, Silver, Gold and Platinum (USGBC, 2016).

\section{CEEQUAL (UK:2003)}

Development of the Civil Engineering Environmental Quality Assessment and Awards scheme (CEEQUAL) was required to deliver more sustainable infrastructure construction (both BREEAM and LEED are focused on buildings). In a similar manner to LEED and BREEAM, it assesses the sustainability of infrastructure projects, through its bespoke rating tool. The CEEQUAL scheme operates during design and construction and evaluates (CEEQUAL, 2007):

- Project Environmental Management

- Land Use

- Landscape

- Ecology and Biodiversity 
- Archaeological and Cultural Heritage

- Water Issues

- Energy

- Use of Materials

- Waste

- Transport

- Nuisance to Neighbours

- Community Relations

The CEEQUAL rating covers a wide range of projects, for example water and sewage systems, rail, tunnels and flood defences. The certification awards are Pass, Good, Very Good and Excellent.

A significant part of the process is the awards presented to civil engineering projects that have excelled in their environmental performance throughout design and construction. The awards intend to raise the environmental performance of all projects.

CEEQUAL is now delivered by BRE and combines some of the attributes of BREEAM.

\section{Greenroads (USA: 2010)}

The Greenroads rating system is specifically for transportation infrastructure, used to "measure and manage sustainability on transportation projects". The Greenroads scheme, while predominantly used in the United States, has been used on projects internationally. The Abu Dhabi Department of Transport was one of the project teams who worked on the development of the Greenroads system. Greenroads credits are grouped into seven categories based on sustainability theme areas and project lifecycle phases (Greenroads, 2010):

- $\quad$ Project Requirements

- Environment and Water

- Construction Activities

- Materials and Design

- Access and Liveability

- Utilities and Controls

- $\quad$ Creativity and Effort

The Project Requirements category defines the minimum steps that must be taken to be Greenroads certified. Greenroads include the Project Requirements to:

- Encourage environmentally responsible decision-making processes

- Have management plans in place for construction

- Establish a minimum baseline for every project that applies for Certification

- Once the baseline requirements have been met, Greenroads projects are certified as Bronze, Silver, Gold and Evergreen.

\section{Other tools}

There are many more sustainability rating tools adopted internationally. For example, in Japan, the Comprehensive Assessment System for Built Environment Efficient (CASBEE) is "the method for evaluating a rating the environmental performance of buildings and the built environment". In Australia, certification of design, construction and operation of buildings is done through Green Star (Green Star). In Qatar, the adopted tool to certify green buildings is the Global Sustainability Assessment System (GSAS).

\section{Sustainability practices and rating tools within the UAE}

\section{Introduction}

Shareef and Altan (2016) provide a comparison between international and Middle Eastern rating tools. They highlight that local sustainability rating tools are important so that the local conditions, regulatory requirements and construction practices are taken into consideration and building performance can be increased.

The Emirates of Dubai, Abu Dhabi and Ras al Khaimah (RAK) have developed local sustainability programmes and rating tools, focussing on the challenges and opportunities specific to the region.

\section{Abu Dhabi - Estidama (UAE: 2008)}

The Estidama system is one of the foundation blocks of Abu Dhabi's Vision 2030 having recognised that "the UAE has almost the highest rate of energy consumption per person in the world (UPC, 2010)". Estidama, which is the Arabic word for sustainability, is an initiative to promote sustainable design and construction in the built environment. Implemented in 2008, it provides resources and procedures, as well as more traditional rating tools, to promote sustainable development.

One initiative within Estidama is the Pearl Rating System. The Pearl Rating System is a rating tool and was designed to ensure sustainability throughout the project life cycle (from design through construction to operation). It has been mandatory for all new buildings in the Emirate of Abu Dhabi since 2010.

The Pearl Rating System (PRS), as a sustainability rating tool, can be used on three types of projects:

- Pearl Community Rating System: Planning

- Pearl Building Rating System: Design and Construction

- Pearl Villa Rating System: Design and Construction

After each assessment, a number of Pearls is awarded, based on the project sustainability. One Pearl is the lowest rating and Five Pearls is the highest. Minimum pearl ratings are required for different structures, as defined in the Estidama regulations (for example, Mosques must achieve a minimum of Two Pearls). 


\section{Abu Dhabi - Other rating tools}

At present in the Emirate of Abu Dhabi there are no other mandatory local sustainability rating tools. For example, projects involving rail, maritime or roads do not require a sustainability assessment.

Dubai - Green Building Regulations and Specification (UAE: 2009)

The Emirate of Dubai incorporated the Green Building Regulations and Specification (GBRS) in 2009. The aims of the regulations were to save energy and water and lower $\mathrm{CO}_{2}$ emissions. The regulations are focused on:

- Envelope Efficiency

- Cooling System

- Water Use

- Indoor Environment Quality

- Energy Efficiency

- Site Heat Island.

It is recognised that the GBRS is not a rating tool (i.e. no classification/award is given) but provides conditions to be followed to meet the green building standards.

Some examples of the minimum requirements include (Dubai Municipality, 2011):

- Recycled Content - at least five percent (5\%) of the total volume of materials used in the construction of the building

- Regional Materials - building materials available regionally must comprise at least five percent (5\%) of the total volume of materials used in the construction of the building.

- Construction and Demolition Waste - at least fifty percent (50\%) by volume or weight of waste material generated during the construction and/or demolition of buildings must be diverted from disposal in landfills. Diverted materials must be recycled or reused.

\section{Dubai - Al Safat (UAE: 2017)}

Dubai has built on the initial foundations set by the GBRS and produced a rating tool; Al Safat. New buildings in Dubai are required to be assessed by the rating tool, those that don't meet the minimum standard will not receive a building permit. A minimum level of sustainability is therefore required for every new building in the Emirate of Dubai (Dubai Municipality, 2017).

The categories assessed by Al Safat:

- Ecology and Planning

- $\quad$ Building Vitality

- Resource Effectiveness: Energy

- Resource Effectiveness: Water

- Resource Effectiveness: Materials and Waste

The rating system classifications are platinum, gold, silver and bronze.

Dubai - Other rating tools

Currently, a minimum rating requirement is required for villas and buildings; however, this does not extend to the other facets of civil engineering such as roads, ports or rail.

\section{RAK - Barjeel (UAE: 2018)}

The Emirate of Ras al Khaimah has recently introduced Barjeel green buildings regulations (2018). They support the United Arab Emirates policies of sustainable development, through the application of minimum requirements for new buildings.

Barjeel is similar in structure to the Green Building Regulations of Dubai. The regulations focus on:

- Energy Efficiency

- Water Efficiency

- Renewable Energy

- Materials and Resources

- $\quad$ Comfort and Well Being

\section{RAK - Other rating tools}

At present in the Emirate of RAK there are no other mandatory local sustainability systems.

\section{The Other Emirates}

Currently there are mandatory sustainable rating tools in place within the Emirates of Abu Dhabi, Dubai and RAK. However, in the remaining four Emirates there are no specific sustainability tools.

\section{Optional accreditation}

Any Emirate(s), developer or project may optionally seek accreditation through an international rating system but there is no mandatory requirement (above and beyond the local requirements).

LEED is the most popular international rating tool in the UAE. The UAE is among the top ten countries in the world by quantity of LEED certifications. There are LEED certified projects in Dubai, Abu Dhabi, Sharjah and Fujairah.

BREEAM has not been used frequently in the UAE but was adopted in Sharjah for the Al Zahia development

To the authors knowledge, CEEQUAL has not been used as a rating tool in the UAE. It has been adopted in the region (for example on Qatar's Inner Doha Re-Sewerage Implementation Strategy (IDRIS) Program). 


\section{Geotechnical sustainability in rating tools}

\section{Introduction}

There are no specific geotechnical rating tools in the UAE so geotechnical sustainability needs to form part of the existing rating tools.

\section{Abu Dhabi - Pearl Rating System}

The rating categories in the Pearl Rating System (the sustainability rating tool part of Estidama) do not have any specific points allocated for geotechnical engineering. In the following categories there is scope for geotechnical engineering to contribute to obtaining credit points (taken from Pearl Building Rating System: Design and Construction):

Integrated Development Strategy encourages a multidisciplinary approach to creating sustainable buildings. The integrated team is required from project inception through to final delivery. Geotechnical engineers should be considered during project development to encourage more sustainable solutions.

The Pearl Building Guide for consultants (UPC, 2010) stresses the importance of assembling an integrated development team; however, geotechnical engineers are not included in the examples provided.

Life Cycle Costing. A portion of the points is available for using Life Cycle Costing to evaluate efficient designs. Early geotechnical input into the overall design solution, efficient geotechnical design and choosing sustainable options can all reduce the quantity of materials needed for construction. In addition, these designs reduce vehicle and machinery operation and reduce extraction of natural materials.

Remediation of Contaminated Land. The site investigation and remediation design are typically done by geotechnical/geoenvironmental engineers; however, the decision to remediate land may be taken before geotechnical engineers are part of the decision-making process. Renewable Energy. Energy geotechnics includes deep geothermal energy extraction, energy piles and geothermal heat pumps (Fragaszy et al. 2011). The decision to incorporate energy geotechnics needs to be taken at the project initiation phase, with geotechnical engineers forming part of the decision-making process.

Building Reuse. Reuse of existing foundations can contribute significantly to a more sustainable project through material reduction, energy reduction and waste reduction. For this to happen, geotechnical engineers would need to be involved early in the decision-making process. The building reuse category is written with the superstructure in mind; however, foundation reuse could also fall into Material Reuse.

Recycled Material. This section promotes the use of recycled steel, cement replacement and recycled aggregates all of which a geotechnical engineer can promote if specifying these items for the foundations, tunnels, pile walls etc.

Reused or Certified Timber. Timber piles are a feasible design option in the region for lightly loaded structures, especially in marine environments.

Innovating Practice promotes innovation that increases sustainability. As there are limited options in the other categories for geotechnical sustainability this category could be used to improve the overall Pearl rating.

\section{Dubai-Al-Safat}

Dubai has relatively recently incorporated Al-Safat, based predominately on the Green Building regulations.

Within geotechnical engineering Al-Safat could only be considered to be relevant to trying to reduce construction and demolition waste. However, the Al-Safat tool considers that "land clearing debris including soil, vegetation and rocks are typically not considered construction and demolition waste."

There is therefore negligible input for geotechnical engineering in the Al-Safat ratings.

\section{Ras al Khaimah - Barjeel}

The categories for review in the Barjeel rating are predominantly focussed on operational efficiency with no consideration of sustainability in building construction. There is therefore no input for geotechnical engineering in the Barjeel regulations.

\section{LEED}

A review of the points available in LEED indicates that there are no direct points specifically for geotechnical engineering. However, it is possible to incorporate aspects of geotechnical engineering in the following sections (taken from LEED Building Design and Construction classification):

Integrative Process promotes a multidisciplinary approach to sustainable design which can include geotechnical engineers.

Environmental site assessment is very similar to Remediation of Contaminated Land in the PRS with similar opportunities and constraints for geotechnical engineers.

Renewable energy production has similarities to Renewable Energy from the PRS and can include geotechnical energy sources.

Building life-cycle impact reduction. In its aim to improve sustainability in products, geotechnical materials can be optimised. Innovation in Design - Recognises innovation in green building categories not specifically addressed by LEED. Geotechnical innovation could be included here.

\section{BREEAM}

In assessing how geotechnical sustainability is included in BREEAM, a review of the New Construction classification was carried out. Project brief and design. A common theme of all rating tools is stakeholder engagement and initial project planning. Within the key design team defined by BREEAM, geotechnical engineers are not listed as an interested party.

Life cycle costing and service life planning. Geotechnical sustainability could contribute here if life cycle costing is used on geotechnical design.

Life cycle impacts. Although this section encourages the use of construction materials with low impacts, it is focussed on the architectural finishes. Encouraging all geotechnical elements to use construction materials with low impacts could be included here. 
Designing for durability and resilience. Although foundation elements are included as part of the checklist, durability design is usually carried out by a structural engineer (though the soil classification is by geotechnical engineers).

Material efficiency. If involved at any early stage, geotechnical engineers can explore the possibility of foundation reuse (if applicable). Geotechnical engineering can contribute to material efficiency in the design stage, especially with foundation and temporary works design. Geotechnical engineers can also help propose alternative means of construction.

Recycled aggregates. Specific credits are available for using recycled aggregate in foundations.

Site selection. The site investigation and remediation design are typically done by geotechnical/geoenvironmental engineers; however, the decision to remediate land may be taken before geotechnical engineers are part of the decision-making process.

Innovation. Geotechnical innovation could earn extra credits in this section.

\section{Greenroads}

Several road projects in Abu Dhabi, managed by Abu Dhabi Department of Transport (ADDOT) have been certified as Pilot Projects with Greenroads. The Emirate of Abu Dhabi is using the Greenroads Pilot Projects to evaluate the performance of the projects and develop a local rating system for infrastructure projects (Abu Dhabi DOT, 2013).

Geotechnical input into the Greenroads assessment includes:

Energy and Carbon Footprint. Geotechnical engineers can help reduce the quantity of virgin materials through efficient design.

Low Impact Development. Geotechnical engineers can provide a review of the soil conditions for drainage conditions; however, this is a management decision and the scope for improving sustainability is limited.

Materials and Design. Although this category does not specifically address geotechnical engineering, there is scope for design input.

\section{Assessment of existing geotechnical sustainable practices in the UAE}

In the United Arab Emirates, the legislative requirement to consider sustainability in a civil engineering project is limited to the mandatory rating tools (e.g. Al-Safat or Pearl Rating System), in certain Emirates (e.g. Dubai), and for certain engineering sectors (e.g. for building, villa and community projects). However, this is not the case in other countries (rating tools are optionally used), so the UAE can be considered to be proactive in civil engineering sustainability.

The number of civil engineering projects which are certified with a non-mandatory rating scheme in the UAE (e.g. LEED) is also relatively high (though the number of civil engineering projects in the UAE is also relatively high). It is evident that there is a desire to improve sustainability in civil engineering projects in the UAE from the Government and developers.

In the wider civil engineering context, there are a large number of projects which do not fall into the mandatory requirements for example, ports, bridges, roads, tunnels, oil and gas plants, airports etc. Nonetheless, most civil engineering projects could be assessed by one of the rating tools.

Currently there are no sustainability initiatives focusing on geotechnical engineering in the UAE. As a result, for geotechnical engineering to make an impact it must be included within the rating tools (either a mandatory UAE system or international certification). The review of the rating tools showed that geotechnical engineering can form a part of the sustainable rating tools but there is potential for development. This includes new rating categories as well as expanding the current classifications.

\section{Practical solutions to increase geotechnical sustainability}

\subsection{Existing tools}

Dubai, Abu Dhabi and RAK have policies on sustainability; however, this is not the case in the other Emirates. The other Emirates should consider mandatory rating tools. Noting that country specific rating tools offer more benefits to project sustainability other Emirates should consider adopting a local standard (e.g. Estidama).

The importance of sustainability in the final product is clear from the focus of the rating tools; over a building's lifetime the energy and water requirements can be significant. However, it is also important that the construction is performed in a sustainable way. The existing local rating tools could be altered to emphasize a reduction in construction materials and the importance of geotechnical engineering in sustainability.

There is more that geotechnical engineering can contribute (within these existing rating tools) to improve sustainability. Although foundations and substructures have the largest potential to improve sustainability, all elements of geotechnical engineering can contribute to sustainable projects:

- $\quad$ reducing water consumption during construction

- reducing materials used, especially in the construction phase

- recycling of earthworks materials for fill and landscaping

- reducing construction and demolition waste

\subsection{A wider scope for mandatory ratings tools}

There are international rating tools that could be adopted to help complement the existing tools which don't cover the full spectrum of key engineering projects. There is continual growth and investment in engineering projects in the UAE and improving sustainability in ports, tunnels, roads, bridges, etc., is necessary as investment continues.

Using the example of road projects, Greenroads (2010) estimate that building one mile of a one-lane transportation project uses about as much energy as 100 average American households use in a year. Given the length and width of new road developments in the UAE, it is clear that more rating tools would help the UAE Government to achieve its aims on sustainability.

Mandatory rating tools should be adopted for large civil engineering projects. Readily available international rating tools could be used and this would provide an instant solution. CEEQUAL, for example, has been delivered on a very wide range of projects (structures, groundworks, transport, energy, waste and water) and therefore offers the most immediate potential for promoting sustainability in the UAE. 
In addition, a rating system for geotechnical projects could be adopted. The CEEQUAL rating system could be used for predominantly geotechnical engineering projects such as:

- Enabling works

- Land remediation

- Slope stability and remediation

- Sea defences

- Embankments / cuttings

It is noted that local rating tools and local categories are beneficial. These could be developed over time to further improve project sustainability.

\subsection{Geotechnical category}

In the assessment of existing geotechnical sustainable practices in the UAE, it was discussed that within the existing rating tools there is scope for greater contribution by geotechnical engineers. This contribution could be achieved by the inclusion of a separate category for geotechnical engineering (an example of a separate category is Vertical Transportation in the Pearl Rating System). The range of possibilities for increasing a project's sustainability (e.g. reduced concrete, steel, waste, emissions etc.) means that the development of a separate geotechnical category would be worthwhile. As almost all projects require geotechnical engineering, this new category should be mandatory for maximum impact.

At present many of the categories focus on operational sustainability. Although over the lifetime of a structure the water used during geotechnical applications (e.g. dewatering, earthworks and foundation design) is significantly less than during operation, there is still the chance to significantly reduce water consumption. A separate geotechnical category would therefore help increase sustainability in the design and construction phase. For example, the category for Water Use does not include any construction water activities (dust suppression, earthworks compaction, concrete mixing, grouting, concrete mixtures etc). However, these items should be addressed as well.

\subsection{Earthworks}

In most of the rating tools, earthworks material removed from site is not considered waste. It is possible that earthworks materials are not considered waste only because they don't require treatment prior to going to landfill (or another final location).

Even if the soil and rock doesn't require treatment there is still all the associated plant and vehicle operations required for excavation, transportation and dumping. In addition to the petrol consumption, hazardous emissions and traffic congestion, all earthworks cause pollution through dust. Given that earthworks have an environmental impact then earthworks should be considered as waste. As a consequence, engineering design, detailed earthworks specifications and construction practices should focus on reducing this quantity:

- Engineering design can match cut and fill quantities, make better use of the existing ground conditions, utilise ground improvement technologies etc.

- The earthworks specifications should be based on actual site conditions, with unsuitable material defined considering the context of sustainability. Furthermore, the specifications could be more prescriptive instead of qualitative (the subcontractor is obliged to meet minimum criteria but can utilise more existing materials).

- Good construction practice includes using laser levels to minimise over excavations.

- Evaluate options to reuse material (e.g. temporary surcharging, permanent landscaping or selling the excess)

A review of the waste sections in the existing rating tools should be carried out. Within the current rating tools there is no benefit in reducing the quantity of soil and rock excavated and transported from site. A separate Earthworks category could be proposed, with the design and construction practices outlined above forming part of the criteria.

It is recognised that reusing earthworks in the current rating system may mean that reduction and recycling rates (e.g. Construction Waste Management) are easily achieved due to the large volumes of soil and rock moved in a typical project. However, this could be addressed through a separate earthworks category or inclusion of a standalone geotechnical category.

\subsection{Integration}

Most of the rating systems promote integration of different disciplines at project inception. The development of procedures to ensure all stakeholders are involved, their plans noted, and the processes recorded, should be conducted on every project. Incorporating sustainability from the very start of a project maximises the opportunities for sustainability. As the project progresses, incorporating sustainability becomes harder.

All disciplines, including geotechnical engineering, should be included in the initial sustainability development meetings. As well as proposing how to incorporate geotechnical sustainability into the project, inclusion encourages interaction with the experts in other disciplines which can lead to improvement and new ideas across the project. Geotechnical renewable energy is a prime example of where integration can be beneficial to a project. Without early engagement the use of energy piles cannot be realised. Inclusion of geotechnical engineers in the integrated development team should be mandatory.

\section{Areas for further research}

Rating tools are the principal way to measure and compare sustainability on a project. Yet there are many limitations; principally time and cost. On small projects there may not be time or budget for a full sustainability analysis; however, this should not be a deterrent in increasing project sustainability. Research should focus on whether it is possible to achieve "practical day to day sustainability" to encourage stakeholders to improve sustainability on projects and change the mindset towards consistent sustainable outcomes.

In geotechnical engineering this issue is particularly acute; there is no agreed method for conducting geotechnical analysis and rating tools are often too complex for analysis. Measuring the environmental performance of foundations can be challenging (BRE, 2016). As a result, rating tools like BREEAM do not tend to include foundations and substructures in its assessment. Building rating tools for geotechnical engineering may be challenging but they need to be developed to increase sustainability. 


\section{Conclusion}

Sustainability now forms part of the national agenda in the United Arab Emirates and as part of this, sustainability during construction and operation of construction projects is recognised as an area where improvements can be made. Rating tools are now frequently used during engineering projects to measure how sustainable a project is and some of the Emirates have developed sustainable rating tools. A review of the ratings tools indicates that geotechnical sustainability has little to no contribution to the overall rating (for both local and international rating tools).

Geotechnical engineering can contribute to making projects more sustainable. Solutions proposed to improve sustainability in the UAE include development of the existing tools, geotechnical subcategories, discipline integration and a focus on earthworks. Standalone geotechnical rating tools could be developed in the future to service projects primarily composed of geotechnical elements.

\section{References}

[1] Abu Dhabi DOT (2013), The Department of Transport in Abu Dhabi Commences Engineering Design of the First Green Road in the Middle East

[2] Barjeel (2019), Green buildings regulations, Ras Al Khaimah Municipality http://www.rakmunicipality.rak.ae/en/pages/rules-regulations.aspx.

[3] BRE (2016), Report of current status on sustainable substructures and foundations, BRE Trust.

[4] BREEAM (2014), BREEAM UK New Construction, Non-Domestic Buildings, BRE Global Ltd.

[5] CASBEE, http://www.ibec.or.jp/CASBEE/english/.

[6] CEEQUAL (2007) Manual - Version 3.1, June 2007.

[7] Dubai Municipality (2011), Green Building Regulations and Specifications. Dubai Municipality, Dubai, UAE greenbuilding@dm.gov.ae.

[8] Dubai Municipality (2017), Al-Safat. Dubai Municipality, Dubai, UAE.

[9] Fragaszy, R. J., et al. (2011), Sustainable development and energy geotechnology - Potential roles for geotechnical engineering, KSCE Journal Civil Engineering, 15(4), 611 - 621. https://doi.org/10.1007/s12205-011-0102-7.

[10] Global Sustainability Assessment System (GSAS), Qatar, https://www.gord.qa/gsas-trust.

[11] Greenroads, https://www.greenroads.org/portfolio.

[12] Green star, https://new.gbca.org.au/green-star/.

[13] Pantelidou H, Nicholson D and Gaba A (2012) Sustainable geotechnics. In Manual of Geotechnical Engineering (Burland J, Chapman T, Skinner $\mathrm{H}$ and Brown $\mathrm{M}$ (eds)). ICE Publishing, London, UK, vol. 1, pp. $125-135$

[14] Shareef and Altan (2016), Building sustainability rating systems in the Middle East, Proceedings of the Institution of Civil Engineers: Engineering Sustainability. https://doi.org/10.1680/jensu.16.00035.

[15] Sochanik, R. (2020), Geotechnical Sustainability in the United Arab Emirates- current status and opportunities, International Journal of Engineering and Technology (IJET), Vol.9, Iss.4, Pages 07-24, September 2020

[16] Statistic Centre Abu Dhabi, https://www.scad.gov.abudhabi/en/pages/default.aspx.

[17] United Arab Emirates (2010), Vision 2021, https://www.vision2021.ae/en.

[18] UPC (2010), Pearl Building Rating System: Design \& Construction, Version 1.0, Estidama, Abu Dhabi Urban Planning Council.

[19] USGBC (2016) LEED v4 for Building Design and Construction -Current Version. USGBC, Washington, DC, USA.

[20] WWF (2016), Living Planet Report 2016, Risk, and resilience in a new era. 